\title{
Desenvolvimento industrial e tecnologia: revisão da literatura e uma proposta de abordagem
}

\author{
Francisco Lima Cruz Teixeira*
}

\section{Resumo}

Este artigo faz uma revisão crítica da literatura que se ocupa em tratar a questão do desenvolvimento tecnológico como parte do desenvolvimento industrial. Em seguida, o artigo apresenta e discute os principais componentes de uma abordagem alternativa a essa questão, aqui chamada de abordagem da economia política.

Palavras-chave: desenvolvimento industrial, aprendizado tecnológico, tecnologia e industrialização

\begin{abstract}
This presents an overview of the theoretical perspectives on industrial development and technological development. It goes further to present the main components of an alternative approach, called political economy approach.
\end{abstract}

Key-words: industrial development, technological learning, technology and industrialization

\section{Introdução}

Este artigo faz uma revisão crítica da literatura que trata do desenvolvimento tecnológico como parte do desenvolvimento industrial, apresentando os principais componentes de uma abordagem alternativa ao tema, aqui chamada de "abordagem da economia política". Embora essa abordagem tenha como ponto de partida os estudos de Albert Hirschman (1958), outros aspectos discutidos na literatura especializada serão incorporados. É especialmente relevante analisar a industrialização por substituição de importações e os efeitos de encadeamento (linkages), o papel do Estado e sua intervenção, o quanto um investimento é apropriado, além das condições de transferência de tecnologia e padrões de financiamento.

Este artigo está organizado da seguinte forma. Na Seção 2, é apresentada uma revisão das principais linhas de pensamento sobre desenvolvimento industrial que tiveram um impacto

considerável no pensamento e no estabelecimento de políticas públicas na América Latina, em especial o estruturalismo da CEPAL e a teoria da dependência. A Seção 3 focaliza os estudos sobre dependência tecnológica e suas ligações com a análise da dependência. Na Seção 4, são discutidos os trabalhos de autores que se ocupam com o estudo da aprendizagem tecnológica e da mudança técnica, em empresas de países em desenvolvimento. Finalmente, na Seção 5, é apresentada a abordagem da economia política, considerada como uma proposta alternativa ao tratamento da questão do relacionamento entre tecnologia e industrialização.

O tema é antigo e andou esquecido por muito tempo, mas retornou com força ao debate acadêmico e à discussão política. Ainda na primeira metade da década de 1990, Goldenstein (1994), propôs repensar a dependência, num momento em que se pensava que a melhor política industrial era não ter política industrial alguma; um conceito que, no Brasil, acabou ganhando um status quase que de verdade absoluta. Contudo, a recente e oportuna tradução do livro de Evans (2004), originalmente publicado em 1995, propõe uma nova abordagem para a análise das políticas industriais. O seu ponto de partida não é a discussão sobre se o Estado deve ou não intervir. A questão é como essa intervenção acontece, pois, tomando como exemplo a tecnologia da informação, observa que todos os países desenvolvidos ou em desenvolvimento adotaram alguma política para esse setor. Mais recentemente, a revista Econômica, da Universidade Federal Fluminense (UFF), apresentou um dossiê sobre política industrial. No artigo de fundo, Kupfer (2003) apresenta evidências que

* Professor titular da Escola de Administração da Universidade Federal da Bahia (EA/UFBA). E-mail: teixeira@ ufba.br. Endereço: Escola de Administração da UfBA Av. Reitor Miguel Calmon, $\mathrm{s} / \mathrm{n}$ - Vale do Canela - Salvador - BA CEP: 40110-100 Artigo aceito para publicação em novembro de 2004 e aceito em março de 2005. 
revelam os mesmos velhos problemas da nossa indústria, com destaque para a defasagem tecnológica que leva à desvantagem em termos de competitividade internacional.

No plano político, a defasagem tecnológica da indústria nacional foi tema da última campanha presidencial brasileira. Diagnosticada uma preocupante "vulnerabilidade externa", os dois principais candidatos lançaram propostas para expandir e requalificar a produção industrial do país, incluindo a "substituição competitiva de importações". Em abril de 2004, o novo governo propôs uma nova política industrial, tecnológica e de comércio exterior, inspirada no velho debate cujas bases este artigo procura identificar.

\section{Abordagem estruturalista da Cepal e a teoria da dependência}

Provavelmente, a primeira tentativa, original, de interpretar o desenvolvimento econômico em países de industrialização recente está ligada aos estudos da Comissão Econômica para a América Latina (Cepal) das Nações Unidas (ONU).

Por volta de 1949, Raul Prebisch - fundador e, durante muito tempo, secretário executivo da comissão apresentou um estudo (PREBISCH, 1950), chamado por Hirschman (1961) de manifesto da Cepal, que lançava as bases para uma análise da América Latina, no que diz respeito a seu desenvolvimento e industrialização. Prebisch partiu do pressuposto de que existia uma assimetria nas relações entre um grupo de nações, que formavam o "centro" do sistema econômico capitalista, e outro grupo que formava a "periferia". Essas relações assimétricas baseavam-se em diferentes estruturas de produção, pois a estrutura do "centro" era vista como essencialmente homogênea, em termos de nível de produtividade entre setores, e diversificada, em termos da quantidade de produtos dirigidos ao comércio internacional. Por sua vez, a "periferia" tinha uma estrutura naturalmente heterogênea, com um setor de exportação atingindo um grau relativamente alto de produtividade, e especializando-se na produção de algumas mercadorias primárias para exportação.

Esse raciocínio levou Prebisch à crítica da teoria de comércio internacional predominante na época. Inspirada na lei das vantagens comparativas, de Ricardo, e mais tarde reformulada por Hecksher, Ohlin e Samuelson, essa teoria estabelecia que a divisão internacional do trabalho traria melhores resultados econômicos a todos os países envolvidos se baseada na dotação natural dos fatores de produção de cada região. Para Prebisch, essa estrutura tendia a perpetuar as desigualdades no desenvolvimento econômico e, até mesmo, a aumentar o fosso entre os países "periféricos" e os "centrais". Primeiro, porque os ganhos do comércio internacional, conforme a evidência empírica (como no caso britânico entre 1876 e 1946), não são igualmente distribuídos. Na realidade, como Singer (1950) também apontou, a taxa de crescimento da produtividade no setor manufatureiro é maior que no setor de produtos primários. Essa tendência é acompanhada no "centro", por um lado, pela organização crescente dos trabalhadores e suas reivindicações salariais e, do outro, pela resistência dos capitalistas, cada vez mais oligopolizados, a reduzirem seus lucros. Essas reações de ambas as partes impossibilitavam qualquer declínio no preço das manufaturas, proporcional ao crescimento da produtividade. Por sua vez, os setores da "periferia" com baixa produtividade (principalmente a agricultura de subsistência) liberavam uma oferta contínua de mão-de-obra, exercendo forte pressão para comprimir os salários no setor moderno.

Esse problema, reforçado pelo baixo nível de sindicalização, não só afetava a demanda interna efetiva, mas também os preços relativos dos produtos primários da "periferia". Além disso, as relações assimétricas tendiam a ser reforçadas pela diferença nas elasticidades-renda dos produtos primários e produtos manufaturados. Enquanto a elasticidade-renda dos produtos primários era vista como um contínuo declínio (lei de Engel), o mesmo não acontecia com os produtos manufaturados, que tinham sua demanda reforçada na "periferia" pelo alto conteúdo de importação dos investimentos correntes e pelos hábitos de consumo baseados em padrões dos países centrais.

A importância do pensamento da Cepal pode ser verificada pela sua influência entre políticos, planejadores e funcionários de governos da América Latina. Esses países passam a adotar uma série de políticas econômicas derivadas das suas propostas, mais tarde identificadas com a estratégia de industrialização por substituição de importações (ISI).Um dos pressupostos básicos da proposta cepalina era a idéia de que o crescimento da 
produtividade, essencial para acelerar o desenvolvimento, só seria possível pela industrialização planejada. Para efetivar as necessárias mudanças, os governos latino-americanos deveriam:

- transferir renda do setor exportador para as novas atividades industriais, através da política fiscal;

- aplicar técnicas de programação econômica para identificar os setores industriais que poderiam ser estimulados;

- estabelecer barreiras tarifárias no nível necessário para proteger a indústria (argumento da "indústria infante");

- ampliar a intervenção estatal para promover e regular as atividade econômicas e, em casos de debilidade por parte da iniciativa privada, garantir a infra-estrutura necessária ou os produtos manufaturados básicos. A intervenção estatal também seria responsável pela internalização do processo decisório, visando à reorientação da velha economia voltada para a exportação;

- atrair e controlar o capital estrangeiro, tanto pela concessão de empréstimos quanto pelos investimentos diretos; e

- tomar medidas para sustentar ou melhorar os níveis salariais, objetivando estimular a capacidade interna de consumo.

Cabe destacar na política da Cepal a ausência de qualquer recomendação quanto ao aspecto tecnológico da industrialização. Embora a diferença de produtividade entre "centro" e "periferia", sustentada pela difusão do progresso técnico na indústria, fosse o ponto central da análise de Prebisch, nenhuma referência explícita é feita à absorção e ao desenvolvimento de tecnologia pelos países periféricos. Apesar de uma certa crença em que o capital e a tecnologia estrangeira pudessem contribuir para as desejadas mudanças técnicas - e, portanto, para o aumento da produtividade, como ressaltado por Cardoso (1980) -, os autores da Cepal não indicaram expressamente como essas novas técnicas seriam incorporadas e desenvolvidas pela nascente estrutura industrial. $\mathrm{O}$ argumento da "indústria infante" parecia fornecer alguma justificativa para o estabelecimento da proteção tarifária. Contudo, pelo menos inicialmente, não houve nenhuma preocupação em indicar, explicitamente, como uma "indústria infante" deveria atingir um nível aceitável de maturidade ou como deveria desenvolver sua própria capacidade para adotar mudanças técnicas (PINTO, 1976). Consequentemente, nenhuma recomendação de política tecnológica foi aventada.

Motivados por críticas ao pensamento original da Cepal e, de acordo com Hirschman (1968), por um certo desencanto com os resultados do processo de industrialização ocorrido na América Latina nos anos 1950, alguns autores (de dentro e de fora da Cepal) começaram a desenvolver uma linha de análise que veio a ser chamada "teoria da dependência".1 A análise da dependência, assim como os primeiros estudos cepalinos, tinha como ponto de partida, as relações assimétricas entre o "centro" e a "periferia". Cardoso \& Faleto (1979), por exemplo, são claros ao enfatizar o papel subalterno desempenhado pela América Latina nessas relações, desde a sua inserção no sistema econômico internacional, através da colonização. Contudo, eles também são claros ao afirmar que as relações de subordinação são reproduzidas pela interação dialética entre a estrutura de classes no "centro" e as estruturas sociais internas de cada país da "periferia". Portanto, a análise do desenvolvimento na "periferia" deve ser baseada numa perspectiva histórica, na qual dois aspectos contraditórios devem ser, igualmente, enfatizados: a dinâmica do capitalismo a nível internacional e as estruturas sociais e políticas internas. Ao que tudo indica, essa versão da análise da dependência preocupa-se, principalmente, com o modo como, através da historia da América Latina, diferentes setores:

\footnotetext{
Na sua resenha bibliográfica, Palma (1981) distingue três versões diferentes da teoria da dependência. Embora a versão que tem em A. Frank seu principal representante deva ser reconhecida pelo grande impacto que causou no debate sobre desenvolvimento, ela fornece poucas referências para se analisar o aspecto tecnológico da industrialização na periferia, pois desde o princípio, não reconhece a possibilidade de desenvolvimento capitalista nesses países. Para uma crítica da versão do "desenvolvimento do subdesenvolvimento" veja, além de Palma (1981), Lall (1975). Para uma crítica marxista ortodoxa, ver Warren (1980).
} 
...das classes sociais desses países se aliaram ou conflitaram com interesses estrangeiros, organizaram formas de Estado, sustentaram ideologias distintas ou tentaram implementar várias políticas ou definiram diferentes estratégias para lidar com ameaças imperialistas em diversos momentos da história (CARDOSO e FALETO, 1979, p.61).

Consoante a sua proposta metodológica, Cardoso e Faleto (1979) distinguiram três períodos básicos no desenvolvimento dependente da América Latina. O primeiro período corresponde ao tempo colonial. Este é seguido pelo surgimento de uma economia exportadora de produtos primários e da organização de Estados nacionais. Finalmente, este último é superado, através da industrialização, por um "desenvolvimento industrial dependente".

Embora essa periodização seja, em geral, aplicável a toda região, Cardoso (1980) é enfático ao distinguir não só as particularidades do desenvolvimento capitalista na América Latina, em oposição a outros casos de industrialização tardia, mas também as especificidades desse desenvolvimento em cada país latino-americano. Por certo, a ênfase na forma particular que o desenvolvimento capitalista assume em cada estrutura produtiva e social é um ponto central dessa análise. Como lembra Palma (1981), partindo dos princípios teóricos gerais da dependência, embora importantes, só é possível derivar análises abstratas e indeterminadas do processo histórico latino-americano. A investigação de situações específicas e concretas seria uma condição necessária para se entender os mecanismos da dependência.

A análise proposta pela escola da dependência enfatiza, também, o dinamismo histórico das estruturas sociais, que se traduz em dois aspectos: os mecanismos de sua autoperpetuação e as possibilidades de mudança (CARDOSO e FALETO, 1979). Assim, a análise histórica da passagem de uma economia exportadora de produtos básicos para um "desenvolvimento industrial dependente", em alguns países da América Latina, é fundamental no trabalho desses autores. Na interpretação deles, a progressiva diferenciação e complexidade da velha economia agroexportadora trouxe consigo, mudanças na estrutura social dominada pelas oligarquias agrárias. No caso brasileiro, o lento começo de uma industrialização incipiente e uma classe média urbana formada por profissionais liberais, pelas burocracias civil e militar e por trabalhadores de escritório.

Por outro lado, a crise internacional dos anos 1930 e, em seguida, a II Guerra Mundial mudaram o contexto no qual a economia agroexportadora havia, até então, operado. A contenção na demanda por produtos primários, implicando crise cambial, levou algumas economias latino-americanas, incluindo a brasileira, a acelerarem o processo de industrialização pela substituição de importações. Em conseqüência disso, a velha aliança de poder, composta pelos cafeicultores e pelas oligarquias regionais associadas aos comerciantes internacionais, foi incapaz de suportar as pressões por mudanças.

A transição de uma economia agroexportadora para a industrialização produziu efeitos profundos não só na estrutura interna de produção, mas também na organização social. A emergência de uma economia industrial moderna implicou a ampliação do mercado interno e o crescimento de uma força de trabalho urbana, além de aumentar a proeminência política da burguesia industrial e da classe média ligada às burocracias. No entanto, os proprietários de terra não foram eliminados politicamente. Um novo pacto político foi estabelecido com a aliança entre as classes emergentes e as oligarquias agrárias.

Assim, o processo de industrialização nos países da América Latina não foi capaz de provocar uma ruptura completa nas condições de dependência do passado. De acordo com os "dependentistas", as mudanças na estrutura de produção não atingiram o setor agrário de subsistência, que manteve seu baixo nível de produtividade. Por sua vez, a falta de hegemonia da burguesia industrial (demonstrada por sua aliança com os latifundiários e sua subordinação ao capital estrangeiro) responde pela manutenção das velhas estruturas produtivas e sociais. Além disso, a industrialização por substituição de importações, fortemente dependente de financiamento internacional, via empréstimos ou investimentos de multinacionais, não foi capaz de internalizar todas as fases do processo de acumulação: além da dependência financeira, as economias periféricas tornaramse, também, dependentes de tecnologia implícita (em equipamentos e máquinas) ou explícita (patentes, licenças etc.). Para Cardoso (1980): 
Basicamente, a situação de dependência é mantida porque, além dos fatores já mencionados, de controle direto pelas multinacionais e dependência de mercados externos, o setor industrial se desenvolve de uma forma incompleta. O setor de bens de produção (Departamento I), que é o ponto central da acumulação numa economia de centro, não se desenvolve completamente. Ordinariamente, os economistas referem-se à "dependência tecnológica" e isso significa que a economia tem que importar máquinas e insumos industriais e, conseqüentemente, tem que estimular as exportações (principalmente de bens primários) para gerar divisas necessárias (apud FRANSMAN, 1982).

A abordagem histórico-estrutural, iniciada pela escola da Cepal e levada adiante pelos autores ligados à análise da dependência, não representa apenas uma importante contribuição teórica ao debate sobre desenvolvimento e tecnologia. As duas linhas de pensamentos inspiraram uma série de estudos sobre a "dependência tecnológica", que serão revisados mais adiante. De qualquer forma, o aspecto principal dessa tradição essencialmente latinoamericana é o fato de que a industrialização e, conseqüentemente, o desenvolvimento tecnológico são processos sociais que não podem ser entendidos se isolados da dinâmica das estruturas social e política nas quais estão inseridos.

\section{Dependência tecnológica}

Influenciados pela análise da dependência, uma série de estudos sobre dependência tecnológica começou a surgir no fim dos anos 1960 e início dos anos 1970. O foco dessas análises era a estrutura industrial incompleta e subdesenvolvida, criada na periferia durante o período de "industrialização dependente", que tinha como uma das suas principais característica, a incapacidade de gerar seus próprios requisitos tecnológicos (dos SANTOS, 1970).

Aqui, cabe observar que mesmo sendo amplamente empregado na literatura, o conceito de dependência, como apontado por Stewart (1978), não é suscetível de uma definição precisa. Mesmo assim, essa autora tenta uma explicação:

A dependência tecnológica surge quando a maior fonte de tecnologia de um país está situada no estrangeiro. No caso de países do Terceiro Mundo, a maior fonte está nos países avançados. A dependência é maior, quanto maior for a extensão do uso da tecnologia estrangeira, e quanto mais concentrada for a fonte (p.116).

Do ponto de vista da dependência tecnológica, duas razões principais respondem por essa situação. Em primeiro lugar, a natureza da industrialização por substituição de importações, na maioria dos países periféricos, implica, desde sua origem, o estabelecimento de indústrias de bens de consumo duráveis, pois havia demanda por esses bens por parte das classes média e alta, concentradas nas cidades. A tecnologia necessária para produzir esses bens já estava disponível; na maioria das vezes, controlada por empresas dos países desenvolvidos. Portanto, o setor industrial da periferia teve seu desenvolvimento baseado na importação dessa tecnologia, tanto através de licenciamentos como de investimentos diretos pelas multinacionais. Essa situação e o fato de existirem sistemas científico e tecnológico desarticulados e "marginalizados" explica porque a tecnologia importada substituiu outras tecnologias que poderiam ser conseguidas com o desenvolvimento científico e tecnológico local (COOPER, 1973).

Em segundo lugar, a dependência é reforçada, de um lado, pela falta de setores de bens de capital e serviços de engenharia bem desenvolvidos, assim como pelo baixo nível de investimento em capacidade tecnológica para melhorar a produtividade industrial, gerar mudanças técnicas ou suprir os insumos necessários a novos investimentos. Por outro lado, a forma pela qual os países periféricos estavam inseridos na economia internacional, bem como a organização das instituições e mercados tecnológicos, também reforça a dependência. Conseqüentemente, o suprimento de tecnologia, como foi observado, sempre ocorre de forma desvantajosa para os países em desenvolvimento. A tecnologia é fornecida em "pacotes" fechados, que excluem a participação local no suprimento de insumos com conteúdos tecnológicos - o que limita o aprendizado local (COOPER e SERCOVICH, 1970) -, ou os termos contratuais incluem cláusulas restritivas 
que impedem esforços inovadores na periferia (VITELLI, 1979). Como resultado, os países da periferia entram no círculo vicioso da dependência "auto-sustentada".

As possíveis consequiências da dependência tecnológica foram amplamente analisadas. Primeiro, os custos da transferência de tecnologia não podem ser quantificados apenas com base no preço pago diretamente pelas informações técnicas e pelos equipamentos. As "imperfeições estruturais" dos mecanismos de transferência tecnológica (CORTEZ, 1976), juntamente com o baixo poder de barganha das empresas dos países periféricos (COOPER e HOFFMAN, 1978), asseguram que custos indiretos, representados por cláusulas contratuais restritivas - que visam assegurar os direitos de propriedade dos detentores da tecnologia e criar outros vínculos comerciais entre compradores e vendedores - estejam, também, envolvidos. Além disso, foram identificadas várias práticas comerciais a que se recorre para maximizar o fluxo de renda para o país onde está a sede da empresa multinacional (VAITSOS, 1974).

Em segundo lugar, a dependência tecnológica sempre foi vinculada à perda de controle sobre decisões econômicas básicas - que envolvem a quantidade e a natureza dos investimentos, nível de preços, quantidades produzidas, distribuição dos lucros etc. - pelas empresas compradoras de tecnologia (STEWART, 1978). Essa situação decorre de investimentos diretos por multinacionais, investimentos financiados externamente, joint ventures, ou mesmo de contratos de licenciamento de tecnologia. No seu estudo sobre a indústria argentina, Sercovich (1984) concluiu que, mesmo no caso de empresas locais, as decisões sobre investimentos e distribuição dos lucros eram bastante influenciadas por circunstâncias fora do controle delas.

Outra conseqüência indesejável da dependência são as "características inapropriadas" das tecnologias importadas às condições dos países subdesenvolvidos (STEWART, 1978). A "inadequação" da tecnologia avançada, algumas vezes chamada de "a questão neoclássica" (STEWART e JAMES, 1982), tem sido constantemente examinada em termos da diferença na disponibilidade de fatores de produção entre o centro e a periferia. A intensidade em capital da tecnologia importada não seria adequada a situações caracterizadas por escassez de capital e abundância de mão-de-obra. Dessa forma, a importação da tecnologia dos países desenvolvidos poderia impedir a implementação de políticas de emprego, entre outras consequiências. Além disso, essas tecnologias raramente são adaptadas ao tamanho e às necessidades dos mercados locais, bem como às matérias-primas disponíveis.

Por último, a maneira pela qual a tecnologia é transferida contribui para a existência de baixos níveis de investimento em capacidade técnica, impedindo, assim, o desenvolvimento de uma capacidade tecnológica local. Embora poucos estudos empíricos tenham investigado essa questão (uma das exceções: MYTELKA, 1978), alguns autores, como Cooper e Sercovich (1970) são enfáticos nas suas observações:

Ao invés de estimular o desenvolvimento de habilidades locais, as transferências tendem a perpetuar a dependência tecnológica. Apesar da tecnologia transferida somar-se ao poder produtivo das economias em desenvolvimento, ela não permite fugir dos seus padrões de exportação. Geralmente, a transferência resulta em altos custos de produção, o que torna os produtos internacionalmente não competitivos. E, o "peso", em termos de divisas resultantes das transferências de tecnologia, é, normalmente, mais alto do que se pode supor (p.38).

Os estudos sobre a dependência tecnológica influenciaram algumas propostas de política em países do Terceiro Mundo. A maioria dessas recomendações objetivou o controle da transferência de tecnologia (UNCTAD, 1972 e 1978), bem como o "desempacotamento" dos componentes de conhecimento técnico, bens e serviços importados (JUNTA, 1976; STPI, 1978). Em conseqüência, vários países estabeleceram mecanismos institucionais para lidar, especificamente, com as transferências de tecnologia. Em alguns casos, foi promulgada legislação de proteção da capacidade tecnológica local, estabelecendo sua participação no fornecimento de insumos técnicos aos projetos de investimento. O objetivo era aumentar o nível de autonomia tecnológica dos países em desenvolvimento.

Entretanto, ainda que tais recomendações promovam o desenvolvimento da capacidade tecnológica local como um passo fundamental rumo à autonomia, elas são, como observado por Maxwell (1981), muito menos 
explícitas e precisas quanto ao modo como atingir esse objetivo. Tratam da necessidade de promover a assimilação e a adaptação da tecnologia externa (JUNTA, 1976) e, também, da criação de um ambiente socioeconômico para o desenvolvimento de tecnologia (UNCTAD, 1978); contudo, não há uma preocupação maior em analisar, exaustivamente, como o processo de acumulação de capacidade tecnológica realmente funciona.

De acordo com Maxwell (1981), esse problema está relacionado com a falta de conhecimento a respeito do processo de "aprendizado". Segundo ele, a literatura que recomenda essas medidas políticas não diz muita coisa sobre os tipos de aprendizado que delas resultarão ou sobre os tipos de trajetória tecnológica das empresas. ${ }^{2}$

A pouca atenção dispensada ao entendimento do processo de mudança técnica (o aprendizado, no caso de MAXWELL) também fundamenta a crítica de Soete (1981) aos aspectos mais cruciais da dependência tecnológica. Para ele, a análise da dependência tecnológica pouco contribui para compreendermos as conseqüências econômicas da dependência tecnológica. Isso decorre da pouca importância dada ao entendimento do nível de mudanças técnicas e de acumulação de capacidade tecnológica nos países subdesenvolvidos, como também da pouca importância atribuída às vantagens de se dispor de inovações transferíveis, como acontece nos países de industrialização recente. Conforme Soete (1981):

Quando discutimos dependência tecnológica, estamos não apenas nos confrontando com conceitos essencialmente dinâmicos, tais como mudança técnica, mas, também, estamos lidando com um conjunto de relações/transações/fluxos cujos custos são facilmente mensuráveis, embora nem sempre os benefícios possam ser totalmente levados em conta (p.181).

Sem dúvida, a literatura sobre dependência tecnológica pouco voltou sua atenção para os aspectos dinâmicos da tecnologia e da mudança técnica nos países subdesenvolvidos. No caso do Brasil, mais importante ainda é o fato de que os estudos sobre dependência tecnológica, ao enfatizarem a ordem econômica internacional, a internacionalização do capital e a imperfeição dos mercados de tecnologias, negligenciaram o impacto que as tecnologias importadas podem ter na estrutura interna dos países em desenvolvimento.

Além disso, essas análises prestaram pouca atenção não apenas aos aspectos dinâmicos das próprias estruturas sociais sob as quais as tecnologias importadas são operacionalizadas, mas também às reações dessas estruturas diante da ameaça da dependência. Portanto, a insistência no caráter "auto-sustentado" da dependência tecnológica parece basear-se, apenas, no aspecto das estruturas sociais que prevalecem em um determinado momento. Conseqüentemente, as possibilidades de mudança, tão importantes para a escola histórica/estruturalista, foram quase totalmente ignoradas.

\section{Literatura sobre aprendizado tecnológico}

A partir do fim da década de 1970, há uma mudança significativa no debate sobre desenvolvimento industrial e tecnologia. ${ }^{3}$ As discussões sobre os mecanismos de transferência de tecnologia, escolha de técnicas, práticas comerciais restritivas e comparações dos orçamentos de ciência e tecnologia dos diversos países dão lugar a questões relativas à natureza e direção do processo de "aprendizado" tecnológico nos chamados "países de industrialização recente" (newly-industrialized countries - NICs). Dessa forma, os esforços foram direcionados para a formulação de uma explicação empírica e teórica dos aspectos dinâmicos da mudança técnica.

Esses novos estudos, sem dúvida, foram inspirados nas pesquisas pioneiras de Hollander (1965) - sobre as fontes de aumento da produtividade numa fábrica nos EUA - e de Enos (1962) - que mostrou o significado

\footnotetext{
2 Maxwell (1981) tem uma abalizada visão geral dessas políticas e seu impacto potencial no processo de aprendizado no âmbito da empresa (especialmente o capítulo 1). Para uma visão comparativa da legislação referente à transferência de tecnologia na América Latina, ver IDB/ECLA (1976).

3 Fransman (1982) sugere que essa mudança de abordagem pode representar uma mudança de paradigma (no sentido atribuído por Kuhn). Enquanto o velho paradigma tinha duas ramificações - uma, baseada na abordagem neoclássica e a outra, na teoria da dependência - o novo paradigma pode ser identificado como "neo-schumpeteriano".
} 
econômico do processo de difusão e melhoramento após grandes inovações na indústria de refino de petróleo. Esses novos estudos também foram estimulados pelas críticas de Nelson e Winter (1977) e de Rosenberg (1976) à tradicional abordagem neoclássica sobre a mudança técnica, centrada no conceito de função de produção.

No entanto, é bem provável que as evidências sobre o desempenho das exportações de alguns NICs tenham sido o principal interesse no processo de aprendizado. Alguns autores (LALL, 1980, 1982; KATZ e ABLIN, 1978) destacaram o fato de que alguns desses países foram capazes de não só desenvolverem uma considerável base industrial, mas também de se tornarem exportadores de produtos industriais. Além disso, esses países se capacitaram para exportar tecnologia sob a forma de bens de capital, serviços técnicos, serviços administrativos ou mesmo plantas industriais, em alguns casos, vinculadas a investimentos diretos no exterior. Essas evidências foram tomadas como crítica importante à perspectiva dependentista "rígida" que considerava impossível o desenvolvimento tecnológico na periferia. Segundo Lall (1975):

Diferentes economias demonstraram habilidade - talvez, calcadas na forte presença de multinacionais e em medidas para integrá-las ao sistema capitalista mundial - para romper com o círculo restrito, previsto pela dependência e outros teóricos do "pessimismo das exportações"... Portanto, o que interessa analisar é porque alguns países menos desenvolvidos (LDCs) são capazes de se integrar com sucesso num sistema dinâmico de comércio capitalista, enquanto outros não são, e saber quais as implicações de se adotar essas políticas de integração para o bem-estar social. Um conceito único de dependência aplicado a todos os LDCs, certamente, não levará a nada (p.805).

$\mathrm{Na}$ análise das origens e da natureza do processo por trás do fenômeno da "exportação de tecnologia", a primeira constatação foi a de que as empresas exportadoras iniciaram sua produção com base em tecnologia importada. De acordo com a interpretação inicial de Lall (1980) e Katz e Ablin (1978), após a primeira compra de tecnologia externa, a empresa entra num processo de "aprendizado". Esse "aprendizado" é, de acordo com Katz (1980), fortemente influenciado pela escolha da técnica adotada. As particularidades do ambiente físico, econômico e social local, bem como as características intrínsecas da informação técnica, tais como a nãoaplicabilidade e o conhecimento imperfeito, fazem com que a função de produção escolhida inicialmente e as mudanças feitas depois não sejam as mesmas em cada país.

Por outro lado, o processo de "aprendizado" responde não só a variáveis internas das empresas ou específicas das técnicas utilizadas, mas também às mudanças macroeconômicas, próprias de cada país. Dessas variáveis, foram identificados o custo do capital fixo, a taxa de crescimento da demanda, a taxa de juros e o nível de proteção tarifária. Dessa forma, a trajetória do "aprendizado" das empresas nos países em desenvolvimento foi caracterizada como, inevitavelmente, de caráter idiossincrático (KATZ, 1980).

Tais constatações se baseiam em estudos de caso empíricos, realizados num programa de pesquisa do BID/Cepal, sobre desenvolvimento científico e tecnológico em vários países latino-americanos (KATZ et al, 1978; DAHLMAN e FONSECA ,1978; MAXWELL, 1977), ${ }^{4}$ que também investigou as origens do aumento da produtividade e a natureza das mudanças técnicas nas empresas desses países. Esses estudos de caso levaram Katz (1972) a identificar o que chamou de "fase de melhoramentos". Essa fase seria caracterizada pelo "aprendizado" adaptativo e por atividades de observação, conduzidas em geral, pelo próprio pessoal das fábricas, algumas vezes organizado em departamentos técnicos. Essas atividades resultaram na implementação de um grande número de pequenas mudanças técnicas em cada fábrica (a maioria das vezes, sem gastos significativos) que, por sua vez, resultaram numa série de melhoramentos que, com o tempo, foram decisivos para melhorar a produtividade.

As evidências empíricas também indicaram que as mudanças técnicas atendem a vários objetivos, dos quais a redução dos custos de produção é apenas um, e não necessariamente o mais importante (KATZ, 1984). As mudanças técnicas podem visar:

\footnotetext{
${ }^{4}$ Sobre a Coréia do Sul e Hong Kong, veja, respectivamente, Westphal e Pursell (1981) e Fransman (1982).
} 
- ao aumento da produção sem efeito significativo na produtividade;

- ao aumento da produtividade dos insumos utilizados;

- à redução dos custos pela mudança na combinação dos insumos; e

- à alteração da composição dos produtos através da adoção de novos modelos, da alteração do balanço entre os produtos existentes ou pela mudança das especificidades técnicas dos produtos existentes (BELL, 1982).

Por causa dessas evidências, duas questões até então recorrentes na literatura passaram a ser consideradas. A primeira foi o que Soete (1981) chamou de "síndrome da grande inovação", descrita por Rosenberg (1976) como uma doença típica da teoria econômica tradicional mas, aparentemente, típica também da dependência tecnológica. Esses novos estudos sobre mudança técnica nos países em desenvolvimento salientaram a importância econômica e técnica das inovações "menores" no ciclo de vida de uma instalação industrial.

A segunda questão refere-se às limitações do conceito de "aprender-fazendo"(learning-by-doing) ao explicar os aumentos de produtividade observados ao longo do tempo. Nesse conceito, está implícita a visão de que a experiência de produção, ou produção acumulada, seria responsável pelo aumento de produtividade ao longo do tempo (ARROW, 1962). Dessa forma, como observado por Maxwell (1981), o "aprender-fazendo" era usado como um conceito amplo para um processo que, na realidade, envolve tipos diferentes de aprendizado. Além disso, esse modelo assumia que a experiência é totalmente adquirida como um subproduto da atividade produtiva, sem implicar nenhum custo.

Por outro lado, não se observava a diferença entre o processo pelo qual a empresa aprende em resposta a problemas na produção e o processo pelo qual esse aprendizado é incorporado em mudanças técnicas reais (BELL, 1982). Ademais, a tradicional teoria do "aprender-fazendo" não considerou a possibilidade de a empresa ter uma estratégia explícita para o aprendizado, incluindo a alocação de recursos e uma organização específica. Dessa forma, o aprendizado foi apresentado como um processo automático e compulsório.

Ao contrário, para outros autores (MAXWELL, 1981), a "estratégia tecnológica" deve ser considerada como uma importante variável no processo de aprendizado. Assim, Maxwell (1981) propõe uma classificação das estratégias da empresa, que varia de "defensiva", passando por "solucionadora de problemas" até "ofensiva". Foi também sugerido que a estratégia de uma determinada empresa possa variar com o correr do tempo, em resposta a variáveis internas e externas. Entre as variáveis externas, certos autores destacam a importância das políticas governamentais para a definição das estratégias individuais das empresas e os seus resultados (MAXWELL,1981; SERCOVICH, 1984).

A evidência empírica sobre o aprendizado em países em desenvolvimento encorajou alguns autores a proporem um modelo "evolucionário" para os esforços pela geração de tecnologia no setor manufatureiro desses países (KATZ, 1980; LALL, 1980). Assim, o processo de aprendizado seguiria um padrão histórico e seqüencial. Dentro desse padrão, uma empresa se deslocaria de tipos de tarefas relativamente menos intensivas em conhecimento para tarefas mais difíceis: de desenho de produto, para o processo de produção, até chegar ao planejamento da produção e engenharia industrial (KATZ,1989).

Em resumo, considerando as evidências sobre a importância e a força da base industrial criada em alguns países de industrialização recente - demonstradas pelas exportações de tecnologia - os estudos sobre aprendizado e mudança técnica tentaram compreender a natureza desse processo dinâmico, até então negligenciado pela literatura especializada. Ao fazer isso, esses estudos tentaram abrir a "caixa preta" tecnológica, analisando os diversos componentes do conhecimento técnico especializado envolvidos na produção industrial. $\mathrm{O}$ desmembramento do velho conceito generalizante de "tecnologia" teve implicações metodológicas importantes, uma vez que a análise da relação entre tecnologia e desenvolvimento industrial deve levar em

\footnotetext{
5 Outros modelos evolucionários foram propostos. Por exemplo, Dahlman e Westphaal (1982) consideraram quatro tipos de atividades: engenharia de produtos, execução de projetos, produção de bens de capital e pesquisa e desenvolvimento. Por sua vez, Kim (1980), tomando como referência a indústria eletrônica da Coréia do Sul, sugeriu um modelo que consiste em três estágios: implementação, assimilação e melhoramento.
} 
conta os diferentes tipos de requerimentos tecnológicos envolvidos em projetos industriais. Esses projetos, por sua vez, podem variar entre setores e incluem habilidades, instituições e mercados totalmente diferenciados.

Alguns autores questionam essas generalizações sobre desenvolvimento tecnológico, implícitas nos estudos sobre o aprendizado nos países recentemente industrializados. O primeiro problema é a representatividade da evidência que indica um nível geral de desenvolvimento nos países do Terceiro Mundo e, como resultado, um movimento na direção da independência tecnológica (BELL, 1982). De fato, os estudos de caso abordados na literatura sobre "aprendizado" foram conduzidos em setores e empresas selecionadas de algumas economias em desenvolvimento (Argentina, Brasil, Índia, México e Coréia do Sul), onde o processo de industrialização tem profundas raízes históricas. Casos de fracasso em economias menos desenvolvidas devem ser considerados (BELL et al., 1982; QUASI, 1983; MLAWA, 1983), quando estamos preocupados em fazer generalizações a partir do aprendizado na empresa em particular.

Da mesma forma, apesar de terem sido mencionadas por alguns autores (KATZ, 1984), as implicações das mudanças na fronteira tecnológica não foram bem enfatizadas. Por um lado, os estudos sobre aprendizado concentraram-se em indústrias consolidadas que, no momento, não estavam passando por mudanças técnicas radicais. Assim, a possibilidade de alcançar a fronteira tecnológica, como imaginado por Katz (1972), na verdade, pode estar corroída pela mudança de alvo; uma questão que é bem resumida por Freeman (1983):

... não é suficiente simplesmente importar a tecnologia de hoje dos países líderes, pois quando ela tiver sido introduzida e suficientemente assimilada, os líderes já terão avançado e a posição relativa dos vários países pode continuar a mesma ou pior do ponto de vista dos seguidores (p.15-16).

Outra questão levantada pelos estudos sobre mudança técnica em países em desenvolvimento é a dos limites do aprendizado; visto basicamente como um processo intra-empresas e evolucionário. O questionamento quanto a esse tipo de aprendizado é sobre se ele seria capaz de colocar uma empresa num patamar mais elevado de desempenho técnico. Como salientado por Bell (1982), outras formas de aprendizado estão envolvidas, como o aprendizado através do treinamento e aquele conseguido pela busca de conhecimento fora da empresa; sem contar que o caminho que leva ao desenvolvimento tecnológico envolve descontinuidades qualitativas.

Sem dúvida, na trajetória evolucionária sugerida por Katz (1980), ou por Lall (1980), não se faz menção às tarefas qualitativamente diferenciadas por um ou por diferentes tipos de tecnologia. Ademais, a passagem de um estágio a outro pode ser apenas uma questão de estratégia da empresa ou de política governamental. Esse ponto é mencionado por O'Brien (1980) na sua análise sobre a emergência de países em desenvolvimento como exportadores de tecnologia. Após descrever as fases de desenvolvimento (mudanças na produtividade, esforços de projeto e esforços de construção) ele afirma que:

A passagem da fase a [das mudanças] para a fase c [dos esforços de construção] não pode ser tratada de forma nenhuma como uma mudança mecanicista, automática ou irreversível. Mudanças qualitativas estão envolvidas, o que pressupõe importantes escolhas que um país pode ou não estar preparado para fazer. Provavelmente, os custos e os riscos aumentam, tanto em termos relativos como absolutos, quando uma economia tenta reforçar sua capacidade tecnológica e atingir autonomia. E as questões referentes a quem arca com os custos e riscos e quem colhe os benefícios dos investimentos bem-sucedidos são, no fundo, políticas (p.1837).

Desde a década de 1990, o aprendizado organizacional é um tema estudado em diversas áreas de conhecimento como a economia industrial, a teoria das organizações, a história econômica, inovações, administração estratégica, psicologia etc. (DODGSON, 1993; GRANT, 1996). As mudanças tecnológicas que se aceleraram a partir da década de 1970 - causando impacto nos produtos, nos processos e nas organizações - e o desempenho de alguns setores industriais do Japão nos anos 1980 renovaram o interesse pelo tema. Para esses estudos a questão do aprendizado não se limita apenas à adoção ou implementação de novas tecnologias no ambiente organizacional. O objetivo é entender como as organizações desenvolvem estratégias, estruturas, processos de trabalho, estilos de liderança, comportamentos e culturas que lhes permitam conseguir um desempenho diferenciado em relação à concorrência. Assim, de acordo com esse ponto de vista, o aprendizado tecnológico 
depende tanto de mudanças na base técnica da produção, como nos processos gerenciais que dão sustentação a essa base.

\section{A abordagem da economia política}

Aqui serão discutidos os principais elementos para uma abordagem alternativa da relação entre industrialização e tecnologia. Serão abordados não apenas alguns tópicos tratados anteriormente, mas também outros aspectos referentes à questão do desenvolvimento, e que são debatidos na literatura afim. A Figura 1 ilustra os principais aspectos da abordagem aqui proposta.

\subsection{Industrialização por substituição de importações e os efeitos do encadeamento}

Hirschman (1968) identificou quatro estímulos diferentes ao processo de substituição de importações na América Latina: guerras, problemas de balanços de pagamento, crescimento do mercado interno (provocado pela expansão das atividades exportadoras) e políticas desenvolvimentistas oficiais. Apesar desses diferentes impulsos originais, entendeu-se que o progresso do processo de substituição de importações se dá por "estágios claramente diferenciados". O setor de bens de consumo final foi o primeiro a aparecer, em substituição aos produtos previamente importados. Só mais tarde, a industrialização atinge "estágios superiores", com a instalação, em diferentes graus e épocas, em cada país, dos setores de bens intermediários e de bens de capital.

Figura 1. Abordagem da economia política

Fonte: adaptado de Stewart (1984).

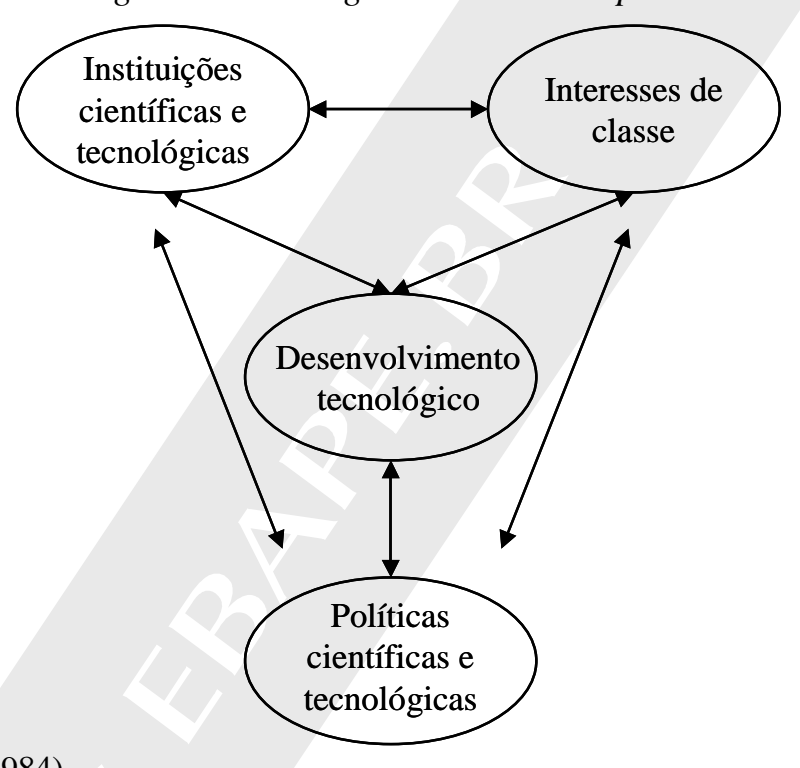

Esse caráter progressivo da substituição de importações marca uma importante diferença entre países que iniciaram a industrialização no século passado e os industrializados recentemente. Como observado por Hirschman (1968), enquanto aqueles países instalaram sua indústria de bens de consumo em paralelo à produção de bens de capital, os países de industrialização recente, ao contrário, buscaram esse processo em insumos e maquinário importados, facilmente disponíveis nas economias avançadas. Além disso, a produção de bens de consumo aumentava a demanda por insumos e máquinas importadas, gerando um processo que, em muitos casos, levou ao endividamento e à dependência de investimentos estrangeiros. Isso teve implicações profundas para todo o processo de industrialização e, particularmente, em relação ao processo de difusão e adaptação de tecnologia, uma vez que não estava havendo experimentação tecnológica nem surgiam inovações próprias, características inseparáveis da industrialização dos países pioneiros.

No entanto, como observado pelo próprio Hirschman, o processo de substituição de importações não tem nenhuma característica intrínseca que possa, definitivamente, impedir o desenvolvimento de um ambiente 
tecnologicamente dinâmico, inclusive, na indústria de bens de capital, através do efeito de encadeamento para trás (backward linkage). No seu clássico estudo, Hirschman (1968) deu grande ênfase aos efeitos do encadeamento no processo de desenvolvimento. Segundo ele, os efeitos do encadeamento poderiam ser perfeitamente aplicados no caso de substituição de importações, pois sob essa estratégia, a industrialização progride a partir de soluções seqüenciais, e não a partir de respostas simultâneas.

Dessa forma, como Hirschman (1968) enfatiza, a natureza das dificuldades que as economias latino-americanas experimentavam para estabelecer sólidos encadeamentos nas suas indústrias deveria ser buscada no terreno da economia política, e não apenas em "quantidades objetivas", tais como tamanho do mercado e economia de escala. Essa observação levou Hirschman a investigar a economia política do efeito de encadeamento. Queria saber quais os determinantes econômicos, sociais e políticos deste. Assim, ao explorar o tema, deu muita ênfase à origem e às motivações políticas dos empresários privados. Por um lado, o fato de que muitos desses empresários, como imigrantes, geralmente não pertenciam às elites tradicionais, poderia ajudar a explicar a relativa fraqueza da sua posição política. ${ }^{6}$ Por outro lado, o próprio processo de substituição de importações implica estímulos contraditórios ao estabelecimento de encadeamentos. Por exemplo: enquanto a presença de uma indústria de bens de consumo cria um mercado para seus fornecedores, o empresário desse setor pode desenvolver uma resistência aos insumos produzidos localmente. De qualquer forma, se a estratégia de substituição de importações não consegue produzir o empresário "desenvolvimentista", as razões devem ser encontradas em outros fatores que não a própria estratégia, conforme enfatizado por Hirschman (1968):

Embora seja verdade que o encadeamento para trás encontra certas resistências e obstáculos, é necessária ainda investigar a existência de outras forças que trabalham no sentido contrário; isto é, no sentido de fazer com que o encadeamento para trás aconteça. Essa avaliação comparativa das "forças e contraforças" é, provavelmente, a chave para entender porque a industrialização tem sido mais vigorosa e contínua em alguns países em desenvolvimento do que em outros - muito antes que eles encontrem quaisquer barreiras de tamanho de mercado (p.20).

\subsection{0 papel das políticas e da intervenção governamentais}

O papel do ambiente institucional na promoção e proteção não apenas da industrialização infante, mas, como observado por Freeman (1983), no desenvolvimento de uma capacidade tecnológica nacional, foi enfatizado, já nos anos 1840, pelo economista alemão List (1904). Um ponto básico das idéias de List era a importância conferida às "políticas econômicas intervencionistas" de longo prazo. Para ele, a política industrial deveria ser vinculada às políticas educacional e tecnológica, para que países como a Alemanha do século XIX pudessem alcançar o desenvolvimento econômico e tecnológico da economia britânica. O conceito de "capital mental" (ou capital intelectual, nas palavras de Freeman) era, para List, um aspecto crucial do desenvolvimento econômico, em paralelo aos investimentos na indústria manufatureira. Idéias semelhantes foram defendidas por Hamilton (1817), em relação à economia norte-americana. Apesar dessas idéias, que influenciaram amplamente as políticas alemã e americana no século passado, as políticas associadas com a estratégia de substituição de importações, como foi visto, parecem ter dado pouca atenção ao aspecto tecnológico da industrialização.

Alguns estudos sobre aprendizado consideram a política governamental uma importante variável interveniente. O impacto das variáveis macroeconômicas na trajetória do aprendizado da empresa foi claramente enfatizado (KATZ, 1980; MAXWELL, 1981). A intervenção governamental mais direta, através de políticas tecnológica e de investimento explícitas, também tem recebido alguma atenção (MAXWELL, 1981; BELL, 1983). De acordo com esses autores, uma característica comum a essas políticas é a limitada preocupação com o dinâmico processo pelo qual as plantas industriais aumentam a produtividade dentro dos limites da capacidade instalada, especialmente, sob um regime de substituição de importações. É uma limitação considerável porque, ainda segundo esses autores, em plantas industriais, o dinamismo pós-investimento não ocorre automaticamente. Ao contrário, trata-se de um processo complexo que necessita ser melhor entendido, particularmente, se o objeto for o estabelecimento de políticas coerentes. De mais a mais, essas políticas devem considerar a relação entre

\footnotetext{
${ }^{6}$ A fraca influência política da burguesia industrial da América Latina foi observada por outros autores. No caso brasileiro, veja Cardoso (1964), para um estudo empírico sobre a ideologia e a representação dessa classe social.
} 
ambos os aspectos da industrialização: o processo de acréscimo de capacidade e o dinamismo incremental subsequente (BELL, 1983).

Sem dúvida, a falta de medidas de política tecnológica que procurem estimular o desempenho pósinvestimento, vinculadas a iniciativas que estimulem o investimento industrial, é um aspecto significativo do processo de industrialização em alguns países. No entanto, poucos estudos a respeito avançaram na tentativa de explicar o que está por trás intervenções governamentais. O que se sabe é muito pouco sobre o que leva os governos a implementarem políticas específicas e quais os interesses envolvidos. Na verdade, os estudos sobre política tecnológica nos países periféricos concentram-se, quase que totalmente, no conteúdo racional, em oposição ao conteúdo social das políticas governamentais e da intervenção estatal. Parece tratar-se de um ponto de vista que assume que o Estado é uma entidade que existe apesar da sociedade. Em conseqüência, raramente são considerados os processos econômico, social e político subjacentes às decisões governamentais. Nesse sentido, o estudo de Evans (2004) dá uma enorme contribuição para esclarecer a questão.

Portanto, uma abordagem político-econômica das decisões relacionadas ao aspecto tecnológico da industrialização permanece na agenda. Como outros autores demonstraram (HERRERA, 1973; SABATO, 1973), a intervenção governamental em assuntos pertinentes ao desenvolvimento tecnológico está extremamente condicionada pelo processo político-social. Este, por sua vez, reflete o papel e o peso das diferentes classes, ou frações de classes (grupos de interesse), dentro de uma determinada sociedade. Logo, a questão a ser abordada diz respeito aos diferentes grupos de interesse envolvidos no processo políticodecisório e à influência relativa de cada um, em confronto com outros interesses.

Embora essas características gerais do processo político subjacentes às políticas industrial e tecnológica possam ser destacadas, a análise abstrata dessas relações tende a esgotar-se. Por conseguinte, a proposta de abordagem baseada na economia política deve prosseguir com análises de situações concretas, onde os diferentes grupos de interesse possam ser identificados e relacionados não só com um determinado conjunto de políticas, mas também com a sua implementação e os seus resultados.

\subsection{Propriedade do investimento, condições de transferência de tecnologia e padrão de financiamento}

O fluxo de investimentos estrangeiros no setor industrial sempre foi uma das razões apontadas na análise da dependência, como responsável pela falta de desenvolvimento tecnológico próprio nos países da América Latina (dos SANTOS, 1970). De acordo com esse ponto de vista, são várias as implicações do investimento estrangeiro direto. Entretanto, em relação ao desenvolvimento tecnológico, dois aspectos foram enfatizados. Em primeiro lugar, a presença de empresas multinacionais pode representar a perda do controle sobre decisões econômicas importantes, incluindo decisões tecnológicas (NEWFARMER, 1979). Em segundo lugar, os investimentos diretos teriam um efeito negativo no processo de formação de capacidade tecnológica nos países da periferia, particularmente, quando as filiais das multinacionais atuam como simples operadoras de "pacotes" tecnológicos, projetados e implantados pelas matrizes, sem a mínima participação local (TIGRE, 1982).

Como alternativa aos investimentos diretos, alguns países estabeleceram medidas políticas, visando garantir a participação local através de joint ventures em empreendimentos industriais. A idéia era que, como proprietários de parte das ações, os investimentos privados ou estatais seriam capazes de reduzir os problemas associados a investimentos diretos. Contudo, como observou Tigre (1982), a associação entre um sócio local e uma empresa multinacional, no que se refere à absorção de tecnologia, não garante nenhuma mudança. Sem dúvida, o sócio estrangeiro pode manter o monopólio sobre as decisões técnicas e gerenciais, especialmente quando o sócio local não é uma empresa industrial com experiência prévia no ramo.

Como já foi visto neste artigo, as condições pelas quais os insumos tecnológicos são importados pelos países periféricos foram amplamente discutidas nos estudos sobre dependência tecnológica. Essas transações envolvem não apenas os custos de curto prazo, mas também os efeitos de longo prazo, associados à aprendizagem tecnológica das empresas. Pensava-se, anteriormente, que as condições adversas vinham do maior poder de barganha dos que forneciam a tecnologia - pelo controle "monopolista" das inovações - e da inexperiência e desinformação dos que a importavam (KATZ, 1972; SERCOVICH, 1984; VITELLI, 1979). 


\section{Referências bibliográficas}

ARROW, M. The economic implication of learning by doing. Review of Economic Studies, June 1962.

BELL, M. Learning and the accumulation of industrial technological capacity in developing countries. Science Policy Research Unity - University of Sussex, 1982.

Technological capacity and the dynamics of industrialization: implications for economic policy in developing countries. [S.I.]: [s.n.], 1983. Mimeografado.

; SCOTT-KEMMIS; SATYARAKWIT, W. Limited learning in infant industry: a case study. In: STEWART, F; JAMES, J. (Ed.). The economics of new technology in developing countries. London: Frances Pinter, 1982.

CARDOSO, F. H. Empresário industrial e desenvolvimento econômico. São Paulo: Difusão Européia do Livro, 1964.

As idéias e o seu lugar: ensaios sobre as teorias de desenvolvimento. Petrópolis: Vozes, 1980.

; FALETTO, E. Dependence and development in Latin America. Berkeley: University of California Press, 1979.

COOPER, C. Science, technology and production in the underdeveloped countries: an introduction. In: COOPER, C. (Ed.). Science, technology and development: the political economy of technical advance in underdeveloped countries. London: Frank Cass, $1973 .$.

; HOFFMAN, K. Transactions in technology and implications for developing countries. Science Policy Research Unity - University of Sussex, 1978. Mimeografado.

; SERCOVICH, F. The mechanism for transfer of technology from advanced to developing countries. Science Policy Research Unity - University of Sussex, 1970. Mimeografado.

CORTEZ, Transfer of petrochemical techonology to Latin America. DPHIL Thesis, University of Sussex, 1976.

DAHLMAN, C.; FONSECA, F. From technological dependence to technological development: the case of Usiminas steelplant in Brazil. Buenos Aires: IDB/ECLA Research Programme in Science and Technology, 1978. (Working paper n.21).

; WESTPHAL, L. Technological effort in industrial development - na interpretative survey of recent research. In: STEWART, F.; JAMES, J. (Ed.). The economics of new technology in developing countries. London: Frances Pinter, 1982.

DODGSON, M. Organizational learning: a review of some literatures. Organization Studies, v.14, n.3, 1993.

DOS SANTOS, T. The structure of dependence. The American Economic Review, v.60, n.2, 1970.

ENOS, J. Invention and innovation in the petroleum refining industry. The rate and direction of inventive activity: economic and social factors. Princeton: National Bureau of Economic Research, Princeton University Press, 1962.

EVANS, P. Autonomia e parceria: estados e transformação industrial. Rio de Janeiro: Editora da UFRJ, 2004.

FRASM AN, M. Learning and the capital goods sector under free trade: the case of Hong Kong. World Development, v.10, n.11, 1982.

FREEMAN, C. Design and British economic performance. Lecture given at the Design Council for the Royal College of Art. Science Policy Research Unity - University of Sussex, 1983.

GOLDENSTEIN, L. Repensando a dependência. Rio de Janeiro: Paz e Terra, 1994.

GRANT, R. M. Toward a knowledge- based theory of the firm. Strategic Management Journal, v.17, winter special issue, 1996.

HAMILTON, A. The soundness of the policy of protecting domestic manufacturers. Filadelfia, PA: JRA. Skerett, 1817.

HERRERA, A. Social determinants of science in Latin America: explicit science policy and implicit science policy. In: COOPER, C. (Ed.). Science, technology and development: the political economy of technical advance in underdeveloped countries., London: Frank Cass, 1973.

HIRSCHM AN, A. Strategy of economic development. New Haven: Yale University Press, 1958.

. Ideologies of economic development in Latin America. Latin America issues, essays and comments. New York: The Twentieth Century Fund, 1961.

The political economy of import substitution in Latin America. The Quarterly Journal of Economic, v.LXXXII, n.1, 1968.

HOLLANDER, S. The sources of increased efficiency: a study of Du Pont Rayon plants. Cambridge, MA: The MIT Press, 1965.

IDB/ECLA. El marco juridico de la innovacion tecnológica in America Latina. Buenos Aires, 1976. (Working paper, n.6).

JUNTA. Andean Pact Technology Policies. Ottawa: International Development Research Center, 1976.

KATZ, J. Importacion de tecnologia, aprendizaje local y industrializacion dependente. Washington, DC: OEA, 1972. 
Domestic technology generation in LDCs: a review of research findings. Buenos Aires: IDB/ECLA Research Programme in Science and Technology, 1980. (Working paper, n.35).

Comparative advantages of Latin American metalworking industries. In:. FRANSMAN, M; KING, K (Ed.). Technological capabilities in the Third World. London: The M acMillan Press, 1984.

"Technology and economic Development: an overview of research Findings, in M. Syrquin and S. TEITEL (eds) , Trade, Stability and quity in Latin America. New York: Academic Press, 1989

; ABLIN, E. From infant industry to technology exports: the Argentine experience in the international sale of industrial plants and engineering works. Buenos Aires: IDB/ECLA, 1978. (Working paper, n.19).

et al. Productivity, technology and domestic efforts in research and development (the grow-path of a Rayon plant). Buenos Aires: IDB/ECLA, 1978. (Working paper, n.13).

KIM, L. Stage of development of industrial technology in developing countries: a model. Research Policy, v.9, n.2, 1980.

KUPFER, D. Política Industrial. Econômica, v.5, n.2, 2003.

LALL, S. Is dependence concept in analysis underdevelopment? World Development, v.3, n.11, 1975.

Developing countries as exporters of industrial technology. Research Policy, v.9, n.1, 1980.

Developing countries as exporters of technology: a first look at the Indian experience. London: The MacMillan Press, 1982.

LIST, F. The national system of political economy. (English translation: Lloyd, S.). [S.I.]: Shongmans, 1904.

MAXWELL, P. Learning and technological change in the steel plant of Acindar S.A. in Rosario, Argentina. Buenos Aires: IDB/ECLA, 1977. (Working paper, n.4).

. Technology policy and firm learning efforts in less- developing countries: a case study of experience of the Argentine steel firm. Thesis (D Phil) - University of Sussex, 1981.

MLAWA, $H$. The acquisition of technology, technological capability and technical change: a study of the textile industry in Tanzania. Thesis (D Phil) - University of Sussex, 1983.

MYTELKA, L. Licensing and technology dependence in the Andean Group. World Developement, v.6, n.1, 1978.

NELSON, R.; WINTER, S. Search of useful theory of innovation. Research Policy, v.6, n.1, 1977.

NEWFARMER, R. Oligopolistic tactics to control marketsand the growth of TNCs in Brazil's electrical industry. The Journal of Development Studies, v.15, n.3, 1979.

O'BRIEN, P. Third World industrial enterprises: export of technology and investments. Economic and Political Weekly, v.XV, n.41/42/43, special number, 1980.

PALMA, G. Dependence and development: a critical overview. In: SEERS, D. (Ed.). Dependence theory: a critical reassessment. London: Frances Pinter, 1981.

PINTO, A. A Cepal e o problema do progresso técnico. Estudos Cebrap, 1976.

QUASI H. Technological Capacity and Production Performance in the fertilizer and Paper Industries in Bangladesh. Dphil Thesis. University of Sussex, 1983.

PREBISCH, R. Technological capacity and production performance in the fertilizer and paper industries in Bangladesh. Thesis (D Phil) - University of Sussex, 1950.

ROSENBERG, N. Perspective on technology. [S.I.]: Cambridge University Press, 1976.

SABATO, J. Atomic energy in Argentina: a case history. World Development, v.1, n.8, 1973.

SERCOVICH, F. C. Brazil. Exports of technology and newly-industrialized countries. World Development, v.12, n.5/6, special issue, 1984.

SINGER, H. The distribution of gains between investing and borrowing countries. American Economic Review, May 1950.

SOETE, L. Technological dependence: a critical view. In: SEERS, D. (Ed.). Dependence theory: a critical reassessment. London: Frances Pinter, 1981.

STEWART, F. Facilitating indigenous technical change in Third World countries. In: FRASMAN, M.; KING, K. (Ed.). Technological capabilities in the Third World. London: The MacMillan Press, 1984.

STEWART, F. Technology and Underdevelopment. Londres: Macmillan, 1978.

; JAMES, J. Introduction. In: The economics of new technology in developing countries. London: Frances Pinter, 1982. 
STPI. Science and technology for development: main comparative report of science and technology policy instruments project. Ottawa: International Development Research Centre, 1978.

TIGRE, P. Technology and competition in the Brazilian computer industry. London: Frances Pinter, 1982.

UNCTAD. Guidelines for the study of the transfer of technology to developing countries. [S.I.]: United Nations, 1972.

. Handbook on the acquisition of technology by developing countries. [S.I.]: United Nations, 1978.

VAITSOS, C. Intercountry income distribution and transnational enterprises. Oxford: Claredon Press, 1974.

VITELLI, G. Imported technology and development of local skills (notes to evaluate the excluding or complementary character of imported technological assets). Institute of Development Studies - University of Sussex, 1979

WARREN, B. Imperialism: pioneer of capitalism. London: Verso, 1980.

WESTPHAL, L.; PURSELL, G. Korean industrial competence: where it come from. World Bank Staff, Paper 469, Washington, DC. 1981. 